Article

\title{
Preparation, Physicochemical Properties, and Long-Term Performance of Photocatalytic Ceramsite Sand in Cementitious Materials
}

\author{
Du Zhao ${ }^{1}$, Fazhou Wang ${ }^{1}$, Peng Liu ${ }^{1,2}$, Lu Yang ${ }^{1}$, Shuguang $\mathrm{Hu}^{1}$ and Wenqin Zhang ${ }^{1, *}$ \\ 1 State Key Laboratory of Silicate Materials for Architecture, Wuhan University of Technology, Wuhan 430070, \\ China; zhaodu76@whut.edu.cn (D.Z.); fzwang@whut.edu.cn (F.W.); chemliup@whut.edu.cn (P.L.); \\ xiaoqiyeting@163.com (L.Y.); sunyue_76@163.com (S.H.) \\ 2 School of Chemistry, Chemical Engineering and Life Science, Wuhan University of Technology, \\ Wuhan 430070, China \\ * Correspondence: wqzhang@whut.edu.cn; Tel./Fax: +86-27-8722-712
}

Received: 26 July 2017; Accepted: 7 August 2017; Published: 11 August 2017

Featured Application: Photocatalytic construction.

\begin{abstract}
Incorporation of $\mathrm{TiO}_{2}$ into cementitious materials is an important technology in the field of photocatalytic pollution mitigation; however, the photocatalytic activity of $\mathrm{TiO}_{2}$ is limited by specific surface area, poor gas diffusion and light transmission performance of cementitious materials. In this study, a novel photocatalytic lightweight aggregate-photocatalytic ceramsite sand (PCS) was synthesized by loading $\mathrm{TiO}_{2}$ on activated porous ceramsite sand (CS) with negative pressure method to solve problems in application of photocatalysts in cementitious materials. Photocatalytic cement material (PCM) was prepared by loading PCS on the surface of cementitious materials, which improved the photocatalytic activity and efficiency of $\mathrm{TiO}_{2}$ in cementitious materials. It was found that the pore structure (pore volume, size distribution and interconnectivity) of ceramsite sand (CS) varies with particle size. The photocatalytic removal rate of benzene on PCS increased significantly through adjusting ceramsite sands in appropriate pore structure and $\mathrm{TiO}_{2}$ at best coating ratio. The photocatalytic activity of PCS slightly decreased but still remained active after incorporated into concrete. $2 \mu \mathrm{L}$ benzene was degraded completely in $200 \mathrm{~min}$ by $5 \mathrm{~g}$ 4PCS-1.25 2.35 and $300 \mathrm{~min}$ by PCM-5, and was still degraded over $80 \%$ in $400 \mathrm{~min}$ by PCM- 5 after exposure to natural environment for 6 months. The results suggested that the photocatalytic activity of $\mathrm{TiO}_{2}$ in cementitious materials was enhanced by the preparation of PCS and PCM, which could provide more gas diffusion, higher specific surface area, more $\mathrm{TiO}_{2}$ active sites, and prevent $\mathrm{TiO}_{2}$ particles from being influenced by the envelope of cement hydration products and the carbonation of cement.
\end{abstract}

Keywords: photocatalytic ceramsite sand; photocatalytic cementitious material; pore structure; $\mathrm{TiO}_{2}$; photocatalytic activity

\section{Introduction}

In recent years, there is an increasing interest in applying photocatalysts in cementitious materials to eliminate urban air pollutants [1-5]. However, cementitious materials have many disadvantages, such as complex constituent, low specific surface area, surface carbonation and poor light transmittance, etc. Previous studies [6-8] showed that the photocatalytic activity of photocatalysts, especially the long-term photocatalytic performance, decreased obviously after being applied in cementitious materials, whether $\mathrm{TiO}_{2}$ was coated on the surface or mixed with the substrates. This phenomenon was attributed to the surface carbonation of gas-solid interface, the peeling of photocatalyst layer 
and the influence of ion species $\left(\mathrm{Ca}^{2+}, \mathrm{Na}^{+}, \mathrm{OH}^{-}\right.$, etc.) [9]. Many studies have attempted to improve the photocatalytic activity of photocatalysts in cementitious materials. Janus et al. [10] prepared cement pastes containing nitrogen and carbon co-modified $\mathrm{TiO}_{2}\left(\mathrm{TiO}_{2}-\mathrm{N}, \mathrm{C}\right)$ to enhance photocatalytic activity of photocatalysts in cementitious materials. Vaish et al. [11] presented visible light active photocatalytic filler based on $\mathrm{BaTiO}_{3}$ and reduced graphene oxide immobilized in Portland cement could be readily reinforced the photocatalytic performance for xanthene dye degradation. Moreover, Lee et al. [12] evaluated the influence of water-to-cement ratio $(w / c)$ on photocatalytic efficiency in the presence of $\mathrm{NO}$ and $\mathrm{NO}_{2}$. It was found that $w / c$ of the material altered the pore structure of cementitious materials [13], the amount of effective surface area available for photocatalytic oxidation and the binding of oxidation products $[14,15]$. Generally, there are two ways to improve the photocatalytic activity of photocatalytic cementitious materials effectively: increasing the absorption of air pollutant and reducing the coverage of photocatalysts by cementitious materials or hydration products [16]. Therefore, some methods such as introducing the high porosity expanded shale into concrete [17], controlling the pore structure of cement pastes [18] and regulating the microstructure of mortar cement [19] have been developed to enhance the photocatalytic activity of photocatalytic cementitious materials.

Aggregates are important components of cement concrete materials, which have potential to act as the substrate of photocatalysts due to the stable composition and structure. Among many aggregates, ceramsite is a promising aggregate to load photocatalysts such as $\mathrm{TiO}_{2}$ because of physicochemical stability and porous structure. It has been applied in exposed aggregate concrete to build concrete pavement and sidewalk for sound absorption and noise reduction in replace of traditional aggregate. In addition, the exposed aggregate concrete exhibited better surface strength and abrasion performance compared with ordinary concrete $[20,21]$. However, the functional ceramsites with large particle size brought some difficulties in construction when being loaded on the surface of cement concrete. Therefore, ceramsites were crushed into ceramsite sands (CS), which could facilely being used in photocatalytic cement material (PCM) to increase the reaction areas of photocatalysis and improve the stability of $\mathrm{TiO}_{2}$ as the intermediate.

In this paper, photocatalytic ceramsite sand (PCS) was prepared by negative pressure method and then loaded on the surface of cement pastes at the initial set. The photocatalytic activity was improved significantly by using CS as intermediate of $\mathrm{TiO}_{2}$ and cementitious materials. Comparing with cementitious materials, PCS could not only prevent the aggregation of $\mathrm{TiO}_{2}$ particles but also provide more active sites, high specific surface areas and more gas diffusion. The preparation of PCS increased the reacting areas and utilization rate of $\mathrm{TiO}_{2}$ in cement concrete constructions compared with coating on the surface or mixing with substrates. Therefore benzene was chosen as target contaminant in experiments which was rarely selected in other studies because of its difficulty in degradation. As we all know, benzene is an organic solvent which is very stable compared with other organic or air contaminants. It is rather hard to degrade especially for photocatalysts applied in cementitious materials. In this study, $2 \mu \mathrm{L}$ benzene was degraded completely in $300 \mathrm{~min}$ by PCM in a closed cylindrical stainless steel gas-phase reactor $(5.56 \mathrm{~L})$, which proved extraordinary photocatalytic property of PCM. The photocatalytic activity of specimens in simulation conditions were studied in detail.

In addition, $X$-ray diffraction (XRD), scanning electron microscope (SEM), energy dispersive spectrometer (EDS), X-ray photoelectron spectroscopy (XPS) and gas chromatography (GC) were conducted to comprehensively characterize the photocatalytic materials and mechanisms governing the catalytic process. 


\section{Materials and Methods}

\subsection{Materials}

CS was obtained from Yi Chang and sieved to three levels of particle sizes $(0.1 \sim 0.6 \mathrm{~mm}$, $0.6 \sim 1.25 \mathrm{~mm}$ and $1.25 \sim 2.35 \mathrm{~mm}$ ). The physical characteristics and the chemical composition are listed in Tables 1 and 2, respectively. ASTM type I was purchased from Huaxin Cement Co., Ltd. (Wuhan, China). Photocatalysts applied in this study, $\mathrm{TiO}_{2}(25 \%$ rutile and $75 \%$ anatase) is Degussa P25, which has a crystal particle size of 25 and $40 \mathrm{~nm}$, respectively. Sodium hydroxide $(\mathrm{NaOH})$ and absolute alcohol $\left(\mathrm{C}_{2} \mathrm{H}_{5} \mathrm{OH}\right)$ were purchased from Shenshi Chem (Shanghai, China). All chemicals applied in this study were analytical grade.

Table 1. The physical characteristics of CS.

\begin{tabular}{ccccc}
\hline Sample & Density Grade & Bulk Density $\left(\mathbf{k g} \cdot \mathbf{m}^{-\mathbf{3}}\right)$ & $\mathbf{1} \mathbf{~ h ~ W a t e r ~ A b s o r p t i o n ~ ( \% ) ~}$ & Total Porosity (\%) \\
\hline Ceramsite sand & 900 & 1100 & 5.6 & 43.57 \\
\hline
\end{tabular}

Table 2. The chemical composition of CS.

\begin{tabular}{cccccccc}
\hline $\mathrm{SiO}_{2} / \%$ & $\mathrm{Al}_{2} \mathrm{O}_{3} / \%$ & $\mathrm{Fe}_{2} \mathrm{O}_{3} / \%$ & $\mathrm{CaO} / \%$ & $\mathrm{MgO} / \%$ & $\mathrm{~K}_{2} \mathrm{O} / \%$ & $\mathrm{~N}_{2} \mathrm{O} / \%$ & $\mathrm{TiO}_{2} / \%$ \\
\hline 64.903 & 18.346 & 7.231 & 0.618 & 2.397 & 3.781 & 1.1 & 0.946 \\
\hline
\end{tabular}

\subsection{Methods}

\subsubsection{Preparation of Photocatalytic Ceramsite Sand}

Ceramsite sand (CS) was activated by being immersed into $0.1 \mathrm{~mol} / \mathrm{L} \mathrm{NaOH}$ aqueous solution with sonication for $30 \mathrm{~min}$ to get more active sites. The other method for activating CS was to immerse $\mathrm{CS}$ into $5 \mathrm{~mol} / \mathrm{L} \mathrm{NaOH}$ at $85{ }^{\circ} \mathrm{C}$ in a reflux device for $4 \mathrm{~h}$. Then, the activated CSs were put into vacuum saturation container at $0.1 \mathrm{MPa}$ vacuum for $30 \mathrm{~min}$ to discharge the air in pores of $\mathrm{CS}_{\text {. TiO }}$ (P25) was firstly dispersed in $100 \mathrm{~mL}$ absolute alcohol with magnetic stirring in various concentrations. After 30 min of vacuum pumping and magnetic stirring, $\mathrm{TiO}_{2}$ absolute alcohol dispersion solution was inhaled into the vacuum container with ultrasonic treatment for $1 \mathrm{~h}$. Then, photocatalytic ceramsite sand (PCS) precursor was taken out, washed by distilled water, and dried at $105^{\circ} \mathrm{C}$ for $3 \mathrm{~h}$. PCS was thus successfully prepared. The concentrations of $\mathrm{TiO}_{2}$ absolute alcohol dispersion solution were designed as 1, 2, 3, 4 and $5 \mathrm{~g} / \mathrm{L}$, respectively. The samples were denoted as mPCS-n, where $\mathrm{m}$ was the coating concentration of $\mathrm{TiO}_{2}$ absolute alcohol dispersion $(\mathrm{m}=1,2,3,4,5 \mathrm{~g} / \mathrm{L})$, and $\mathrm{n}$ was the particle size of CS ( $\mathrm{n}=0.1 \sim 0.6,0.6 \sim 1.25,1.25 \sim 2.35 \mathrm{~mm}$ ). To compare PCM in this study with traditional photocatalytic cementitious materials, control groups were prepared in traditional ways by spraying $\mathrm{TiO}_{2}$ on the surface or incorporating into cement pastes with same amount of photocatalysts $(0.1 \mathrm{~g})$ and same dimension compared with other samples. The photocatalytic activity of pure $\mathrm{TiO}_{2}(\mathrm{P} 25)$ was also tested. The experimental devices and procedure are shown in Figure 1. 


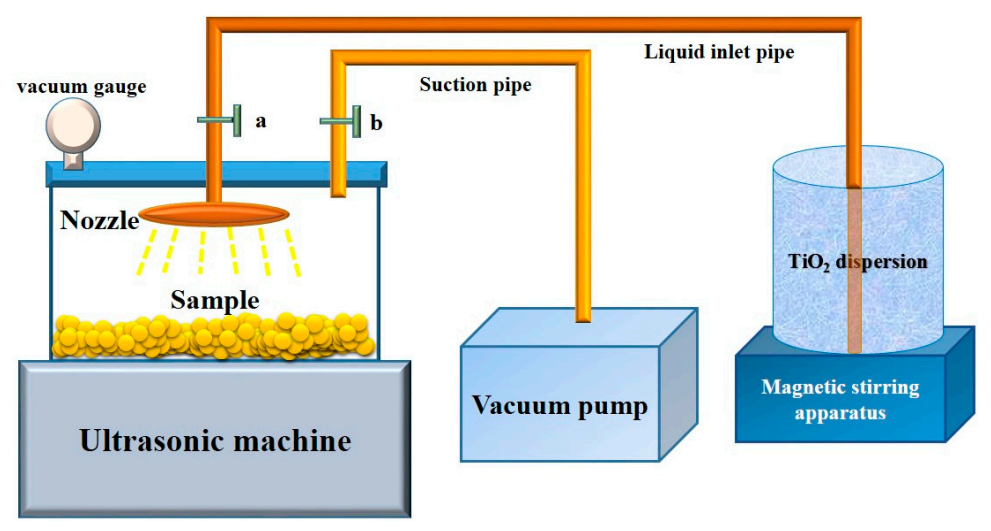

Figure 1. Diagram of the vacuum-ultrasonic-negative pressure devices.

\subsubsection{Preparation of Photocatalytic Cement Materials}

The photocatalytic cement materials (PCM) were prepared with 4PCS-1.25 2.35, cement and water. First, cement and water $(w / c$ is 0.35$)$ was mixed for $3 \mathrm{~min}$ in cement mixer. After the cement pastes were cast into a petri dish (diameter $90 \mathrm{~mm}$ ) for $3 \mathrm{~h}, 1,3,5 \mathrm{~g}$ 4PCS-1.25 2.35 was sprayed on the top surface of the cement pastes, respectively. PCS was thus exposed to air. After 3 days of hydration, PCM was successfully prepared. The samples were denoted as PCM-x, where $\mathrm{x}$ is the weight of 4PCS-1.25 2.35 ( $\mathrm{x}=1,3,5 \mathrm{~g})$.

\subsection{Characterization}

The crystalline compositions of PCS were identified by XRD (MAX-RB RU-200B) (Rigaku, Tokyo, Japan) at the scanning speed of $8^{\circ} \mathrm{min}^{-1}$ and scanning range from $10^{\circ}$ to $80^{\circ}$ [17]. The scanning electron microscopy (SEM) images were obtained through SEM (Quanta FEG 450, FEI) analyzer (FEI, Hillsboro, OR, USA), together with Genesis EDS for compositional analysis. Chemical valence states of PCS were investigated by X-ray photoelectron spectroscopy (XPS), which was performed on a Thermo Fisher ESCALAB 250Xi instrument (Thermo Fisher Scientific, Waltham, MA, USA) with an monochromatic Al K Alpha $(1486.68 \mathrm{eV})$ X-ray source. The apparent morphology of CS, PCS and PCM were observed by digital camera. The specific surface area was measured from $\mathrm{N}_{2}$ adsorption isotherms by Brunauer-Emmett-Teller surface area measurement (BET, ASAP 2020M, Atlanta, GA, USA). The pore size distribution, available pore volume and total porosity of CS and PCS were determined by Mercury intrusion porosimetry (Pore Master 60, Quantachrome, Boynton Beach, FL, USA). The working pressure was $3.45 \mathrm{kPa} \sim 413 \mathrm{MPa}$, allowing mercury intrusion in pores with diameters $1 \mathrm{~nm} 350 \mu \mathrm{m}$.

\subsection{Evaluation of Photocatalytic Activity}

The photocatalytic activity was characterized in mineralization of benzene. The source of UV light was a high pressure $\mathrm{Hg}$ lamp $\left(125 \mathrm{~W}, \lambda_{\mathrm{nm}}>340 \mathrm{~nm}\right.$, light spectrum around 365, 400, 440, 550 and $580 \mathrm{~nm}$ ), which was obtained from Shanghai Yaming, China. There was a $15 \mathrm{~cm}$ distance between the lamp and sample. In these tests, the UV light region on the surface of sample was 320 400 nm and the UV intensity was $0.96 \mathrm{~mW} / \mathrm{cm}^{2}$.

Samples were put in a closed cylindrical stainless steel gas-phase reactor $(5.6 \mathrm{~L})$ with a quartz window. Gaseous environment was synthetic air and humidity was indoor humidity. For each test, liquid benzene $(2 \mu \mathrm{L})$ was injected and evaporated in the reactor. After complete evaporation of benzene in the reactor (shown by concentration in gas chromatograph), a sample of PCM or $5 \mathrm{~g}$ PCS was started to be irradiated by the UV lamp. Then, the concentration of benzene in the photocatalytic progress was measured every 15 min by gas chromatograph (GC9560, Shanghai, Huaai, China). 
The PCSs with coating concentrations of $\mathrm{TiO}_{2} 1 \sim 5 \mathrm{~g} / \mathrm{L}$ were used in recycled experiments. The approach is as follows: after the first photocatalytic activity test, the sample was irradiated under a UV lamp for $1 \mathrm{~h}$ with the quartz window open to ensure the pollutants absorbed on the surface of sample removed completely. Then, seal the reactor again and start the next test. PCM-5 was applied in long-term photocatalytic effect test. The sample was placed on the roof (State Key laboratory of Silicate Materials for Architecture, Wuhan University of Technology, Luoshi Road, Wuhan, Hubei, China) with the face up for 6 months (September 2015 to March 2016). The outdoor temperature was $-6 \sim 38^{\circ} \mathrm{C}$ and the relative humidity conditions range from 35 to $90 \%$. The month average rainfall was $118.9 \mathrm{~mm}$. After 6 months of atmospheric environment exposure, the photocatalytic activity of PCM-5-6 months was evaluated under same experimental conditions with other samples. The control group was also tested after 1 month of atmospheric environment exposure.

\section{Results and Discussion}

\subsection{Physical and Chemical Properties}

Figure 2 showed the surface morphology of CS and PCS with different particle sizes. The samples were denoted as CS-n and mPCS-n, where $m$ was the coating concentration of $\mathrm{TiO}_{2}$ absolute alcohol dispersion $(\mathrm{m}=1,4 \mathrm{~g} / \mathrm{L})$, $\mathrm{n}$ was the particle size of CS $(\mathrm{n}=0.1 \sim 0.6,0.6 \sim 1.25,1.25 \sim 2.35 \mathrm{~mm}$ ). No apparent color differences were observed between CS-0.1 0.6 and 1PCS-0.1 0.6. In addition, 1PCS-0.6 1.25 was a little whiter than samples without coating. Nevertheless, all PCS of the particle size 1.25 2.35 mm were obviously whiter compared with the control samples without coating, which was consistent with Yang's study [17]. The change of color was attributed to the light absorption and reflection of $\mathrm{TiO}_{2}$ particles [22]. As we can see, $\mathrm{PCS}$ with $\mathrm{TiO}_{2}$ dispersion solution concentrations $4 \mathrm{~g} / \mathrm{L}$ were significantly whiter than that of $1 \mathrm{~g} / \mathrm{L}$, which was related to more $\mathrm{TiO}_{2}$ coating areas and thicker $\mathrm{TiO}_{2}$ coating layer. The surface topography of PCM with 1, 3, $5 \mathrm{~g}$ PCS loaded and interface between PCS and matrix are shown in Figure 2 as well.

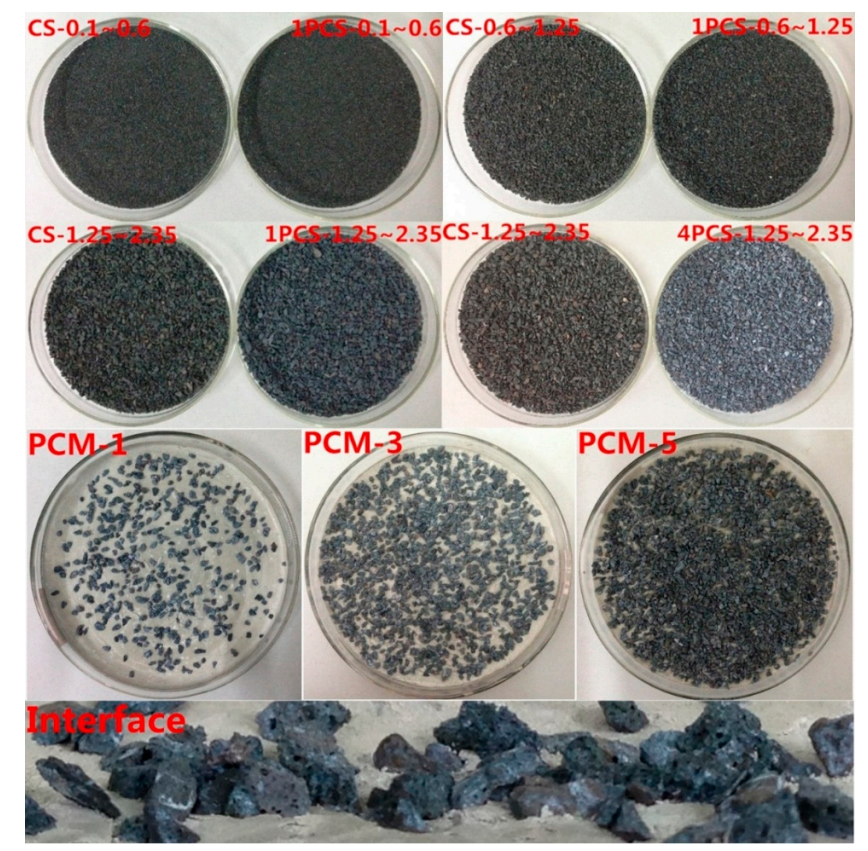

Figure 2. Surface morphology of photocatalytic ceramsite sand and photocatalytic cement materials and the interface of PCS and cement; CS-n and mPCS-n (m was the coating concentration of $\mathrm{TiO}_{2}$ absolute alcohol dispersion, $\mathrm{m}=1 \sim 4 \mathrm{~g} / \mathrm{L}$, $\mathrm{n}$ was the particle size of $\mathrm{CS}, \mathrm{n}=0.1 \sim 0.6,0.6 \sim 1.25,1.25 \sim 2.35 \mathrm{~mm}$ ); PCM-1, 3, 5 (photocatalytic cement materials with 1, 3, 5 g PCS); PCS: photocatalytic ceramsite sand; CS: ceramsite sand; PCM: Photocatalytic cement material. 
XRD patterns were applied to explore the crystalline structure of samples. Figure 3 showed the XRD patterns of CS, $\mathrm{TiO}_{2}$ (P25) and 1PCS-1.25 2.35 with ultrasonic activation (1PCS-1.25 2.35-UA) and alkali activated (1PCS-1.25 2.35-AC). It can be seen that the main components of CS were $\mathrm{SiO}_{2}$ and $\mathrm{Mg}_{0.7} \mathrm{Fe}_{0.23} \mathrm{Al}_{1.97} \mathrm{O}_{4}$. Comparing with the XRD pattern of $\mathrm{TiO}_{2}$, the characteristic peaks of 1PCS-1.25 2.35-UA occurred at about $2 \theta=27^{\circ}$ and $44.3^{\circ}$ can be assigned to the Rutile [23]. The characteristic peaks at $2 \theta=25.3^{\circ}$ can be assigned to the Anatase. The peak of $\mathrm{TiO}_{2}$ could also be found in 1PCS-1.25 2.35-AC, but weaker than 1PCS-1.25 2.35-UA. The XRD suggested that $\mathrm{TiO}_{2}$ particles were successfully coated on the surface of CS and ultrasonic activation could get more actives sites for combination of $\mathrm{CS}$ and $\mathrm{TiO}_{2}$.

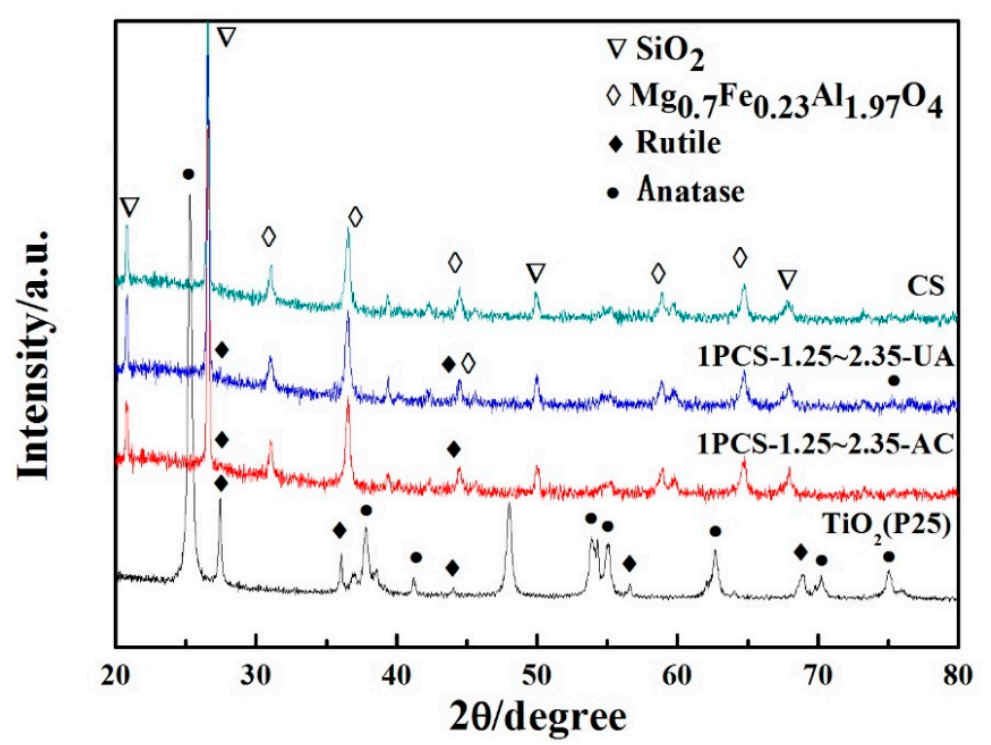

Figure 3. X-ray diffraction patterns of $\mathrm{CS}, \mathrm{TiO}_{2}$ (P25), 1PCS-1.25 2.35 with ultrasonic activation (1PCS-1.25 2.35-UA) and alkali activated (1PCS-1.25 2.35-AC).

SEM images in Figure 4 presented the morphological structure of CS, 4PCS-1.25 2.35, and 1PCS-1.25 2.35, respectively. From Figure 4a,b, it can be seen that the pore size of CS mainly ranged from 5 to $50 \mu \mathrm{m}$ and there are some small pores under $1 \mu \mathrm{m}$. Some inter-connecting pores were also observed clearly, which could facilitate the coating of $\mathrm{TiO}_{2}$ and the absorption of gas pollutants. Figure $4 \mathrm{c}$, d showed that $\mathrm{TiO}_{2}$ was coated on the surface of CS successfully. It can be found $\mathrm{TiO}_{2}$ was layered homogeneously on the surface of CS and there were abundant small holes among $\mathrm{TiO}_{2}$ layers, which could contribute to the absorption of gas pollutants. There are three factors to form those structures, including silica-based CS, ultrasonic activation and negative pressure preparation method. These factors were helpful to produce hydroxyl groups on the surface of CS and therefore lead to the formation of Ti-O-Si bonds and the accumulation of $\mathrm{TiO}_{2}$ particles [24,25].

$\mathrm{TiO}_{2}$ particles on the surface of 1PCS-1.25 2.35 were observed In Figure 4e, which were seen as bright spots. It was confirmed that $\mathrm{TiO}_{2}$ particles loaded on the surface of CS agglomerated rarely. The observation in Figure 4e was in agreement with the results of EDS in Figure 4f,g. Element Ti could be identified at Area 1 where many bright spots could be observed. Meanwhile, Area 2 contained no Ti had no bright spot. The result of EDS showed that $\mathrm{TiO}_{2}$ had deposited on the surface of PCS successfully.

BET was applied to explore the specific surface area of samples. As shown in Table 3, the specific surface area of CS and mortars are $0.0770 \mathrm{~m}^{2} / \mathrm{g}$ and $0.0013 \mathrm{~m}^{2} / \mathrm{g}$, respectively. The specific surface area of CS is much higher than that of mortars. 


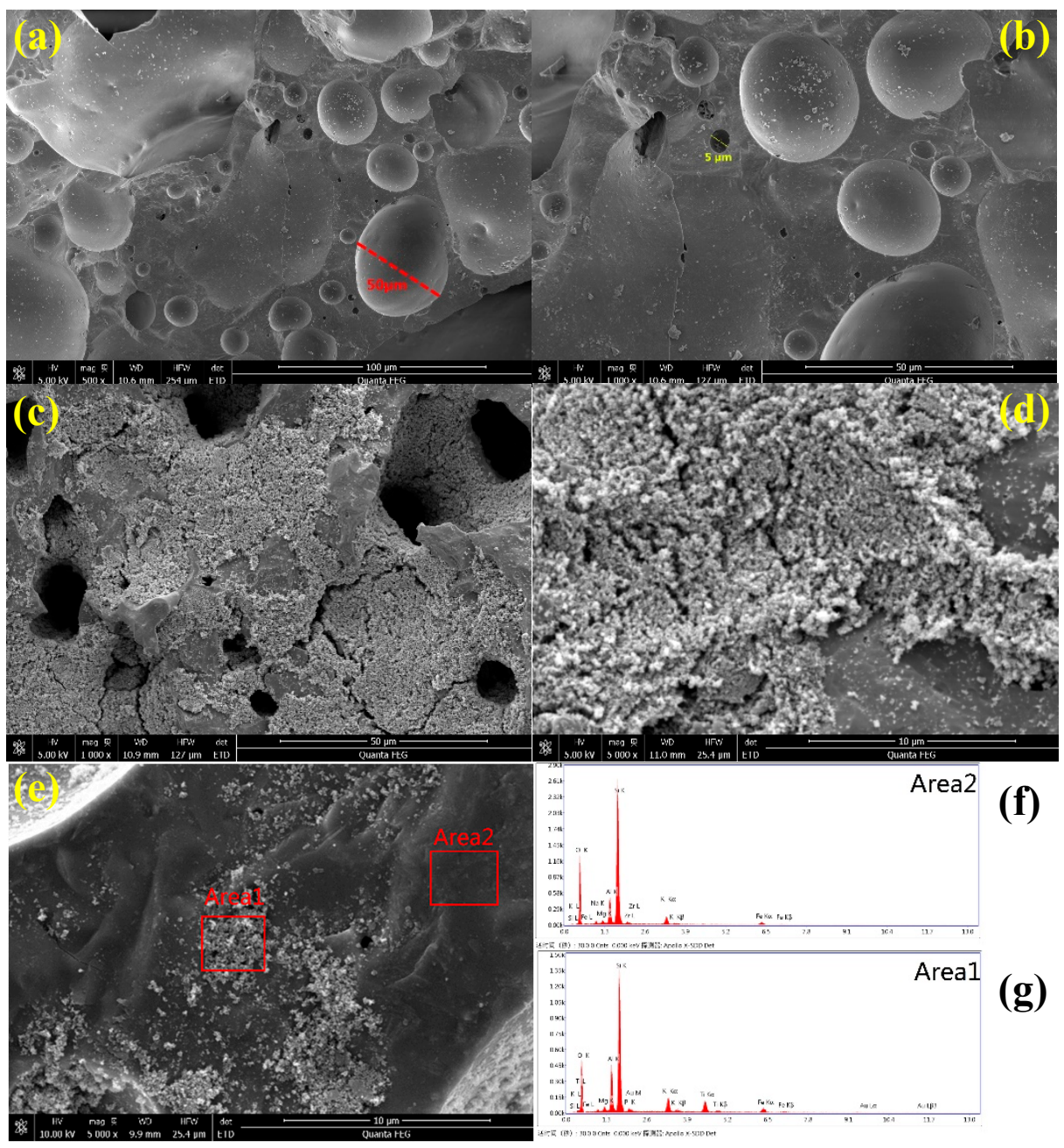

Figure 4. Surface morphology and EDS of CS and PCS; $(\mathbf{a}, \mathbf{b})$ surface morphology of CS-1.25 2.35; (c,d) surface morphology of PCS (4PCS-1.25 2.35); (e-g) surface morphology and EDS patterns of PCS (1PCS-1.25 2.35); EDS: energy dispersive spectrometer.

Table 3. BET results of CS and mortars.

\begin{tabular}{cc}
\hline $\mathrm{CS}\left(\mathrm{m}^{2} / \mathrm{g}\right)$ & Mortars $\left(\mathrm{m}^{2} / \mathrm{g}\right)$ \\
\hline 0.0770 & 0.0013 \\
\hline
\end{tabular}

Figure 5 and Table 4 showed the pore size distribution, total porosity and available pore volume for all PCS samples. Figure 5a revealed that PCS exhibited a pore size distribution mostly in the range of $1 \sim 100 \mu \mathrm{m}$, with a small amount of pores from 10 to $1000 \mathrm{~nm}$. The pores distributed in the range of 10 1000 nm increased with the increase of the PCS particle size while the pores distributed in the range of 1 100 $\mu \mathrm{m}$ decreased with the increase of the PCS particle size. In other words, when CS was crushed into smaller pieces, many small pores of CS were lost but the amount of larger pores increased. This might be because some small pores at section were destroyed through the crushing, while some larger closed pores turned to open. Therefore the CS with small particle size had higher total porosity and pore volume than larger ones (as shown in Table 4). More big pores, higher porosity and pore volume might cause the waste of $\mathrm{TiO}_{2}$ particles, because the $\mathrm{TiO}_{2}$ particles at the bottom of the pores could not accept the light. In addition, big pores were nearly useless to gas diffusion compared with small ones. Figure $5 \mathrm{~b}$ showed the similar pore distribution curves for the samples prepared with different $\mathrm{TiO}_{2}$ coating concentrations. The pore volumes of PCS with different $\mathrm{TiO}_{2}$ 
coating concentrations had few changes, corresponding to the results of Figure $5 \mathrm{~b}$. With the increasing of $\mathrm{TiO}_{2}$ coating concentrations, the pores between $90 \mu \mathrm{m}$ and $100 \mu \mathrm{m}$ reduced slightly while the pores in the range of 1 1000 nm increased. This phenomenon can be attributed to the formation of $\mathrm{TiO}_{2}$ layer provided many small pores and reduced the pore size of some big pores. According to the above results, it can be inferred that PCS-1.25 2.35 might possess more excellent photocatalytic performance due to appropriate pore structure (more pores in the range of 10 1000 nm, relatively lower total porosity and pore volume), which could provide an excessive exposure of $\mathrm{TiO}_{2}$ and more gas diffusion channels.

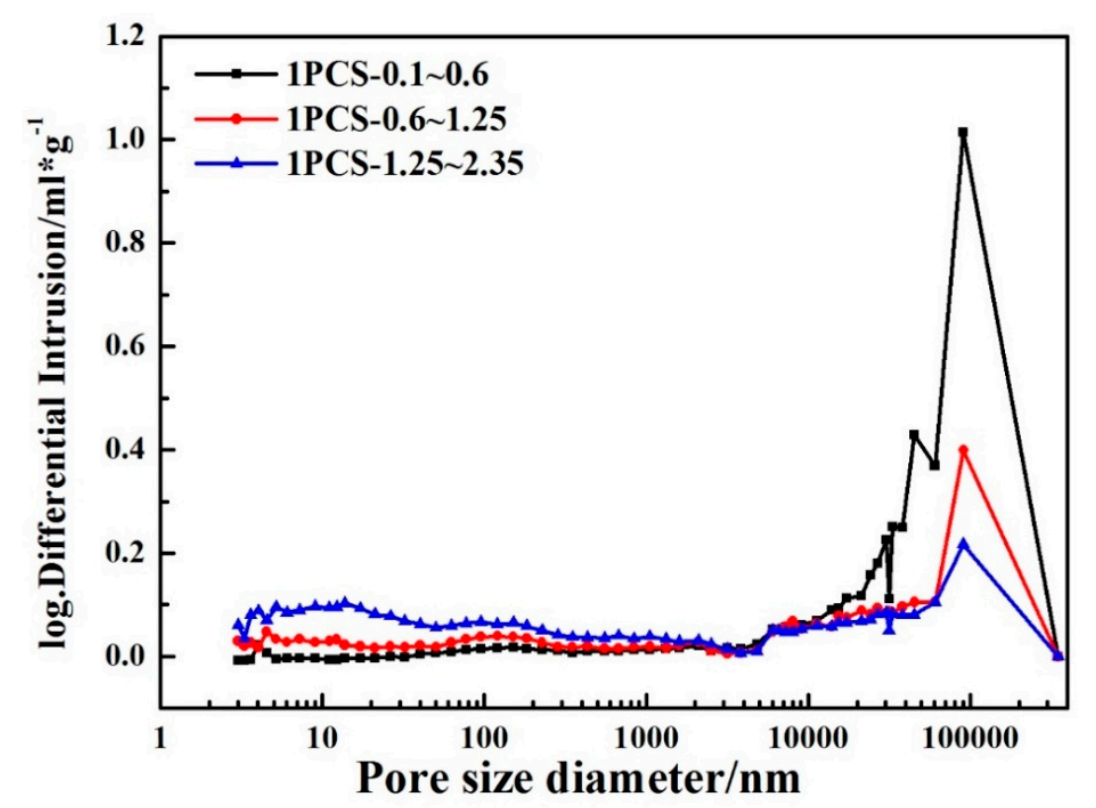

(a)

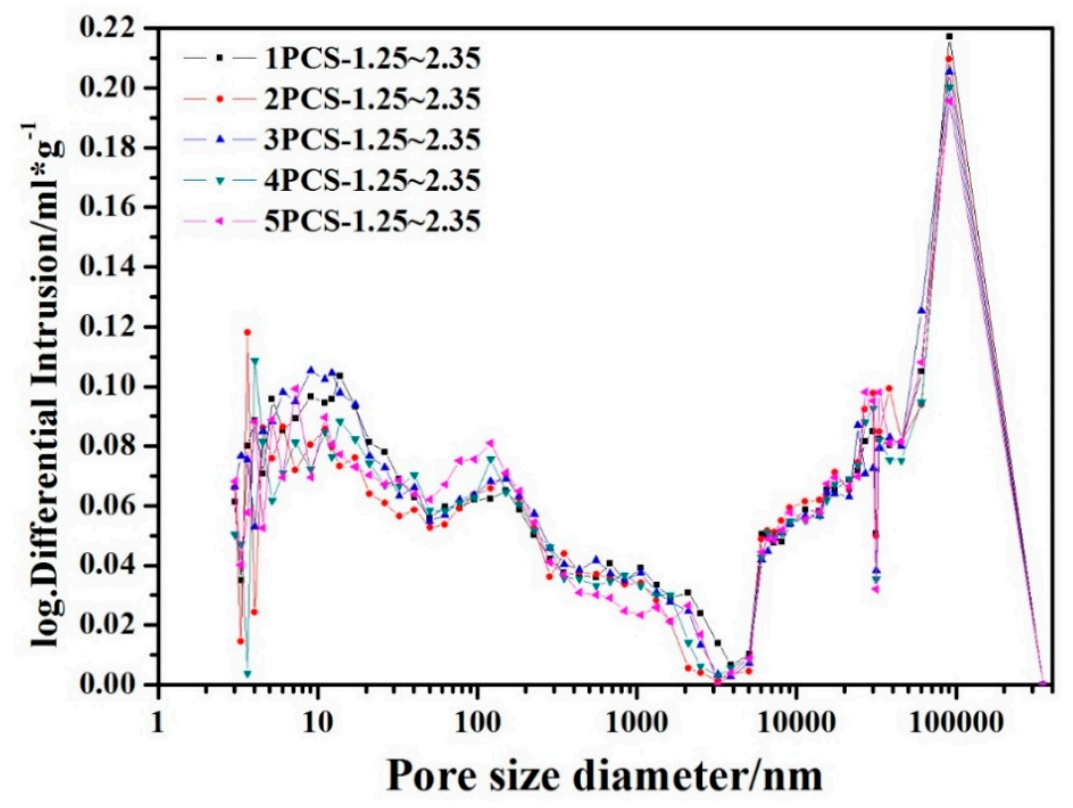

(b)

Figure 5. The pore distribution of all PCS samples; (a) 1PCS- $\mathrm{n}$, $(\mathrm{n}=0.1 \sim 0.6,0.6 \sim 1.25,1.25 \sim 2.35 \mathrm{~mm}$ ); (b) $\mathrm{mPCS}-1.25 \sim 2.35,(\mathrm{~m}=1,2,3,4,5 \mathrm{~g} / \mathrm{L})$. 
Table 4. The total porosity and pore volume of all PCS samples.

\begin{tabular}{ccc}
\hline Sample & Total Porosity $\mathbf{( \% )}$ & Pore Volume $(\mathbf{m L} / \mathbf{g})$ \\
\hline 1PCS-0.1 0.6 & 61.19 & 0.8438 \\
1PCS-0.6 1.25 & 43.00 & 0.4053 \\
1PCS-1.25 2.35 & 43.38 & 0.3973 \\
2PCS-1.25 2.35 & 41.83 & 0.3655 \\
3PCS-1.25 2.35 & 42.72 & 0.4070 \\
4PCS-1.25 2.35 & 41.97 & 0.3706 \\
5PCS-1.25 2.35 & 42.84 & 0.3806 \\
\hline
\end{tabular}

In order to further identify the chemical composition of PCS before and after $\mathrm{TiO}_{2}$ loading, XPS analysis was carried out. The XPS spectra survey patterns of $\mathrm{Mg}, \mathrm{Fe}, \mathrm{O}, \mathrm{Ti}, \mathrm{C}, \mathrm{Si}$, and $\mathrm{Al}$ peaks are showed in Figure 6a, indicating the elemental components and their chemical states of PCS, which are consistent with the XRD results. The $\mathrm{C} 1 \mathrm{~s}$ peak correspond to organic and inorganic carbon, which represent the pollution peak. The O1s characteristic peaks can be deconvoluted into four peaks at $529.6,530.8,531.9$ and $532.5 \mathrm{eV}$, which can be assigned to Ti-O-Ti, Al-O-Al, Ti-O-Si and Si-O-Si, respectively [26]. The Al-O-Al bonds might be caused by the calcination of CS [27]. The bonding of titanium and silicon (Ti-O-Si) is supported by peaks centered at $531.6 \mathrm{eV}$, formed by the combination of $\mathrm{Ti}-\mathrm{O}-\mathrm{H}$ bond and $\mathrm{Si}-\mathrm{O}-\mathrm{H}$ bond. The binding energy of $\mathrm{Ti}-\mathrm{O}-\mathrm{Si}$ is $531.6 \mathrm{eV}$ because the $\mathrm{O} 1 \mathrm{~s}$ binding energy of $\mathrm{Si}-\mathrm{O}$ bond was weakened by the formation of $\mathrm{Ti}-\mathrm{O}-\mathrm{Si}$ and the electron density of $\mathrm{Si}$ is higher than $\mathrm{Ti}$ [28]. The formation of Ti-O-Si bond confirmed that $\mathrm{TiO}_{2}$ was loaded on the surface of CS by chemical bond, which is tighter than physical connection and could improve the catalysis durability of PCM effectively [29].

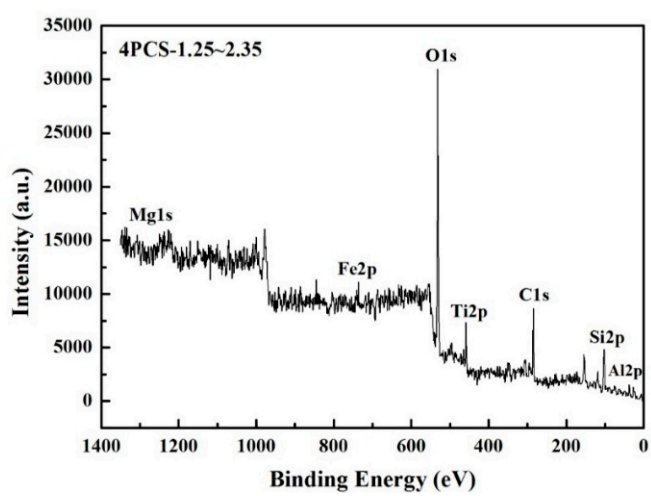

(a)

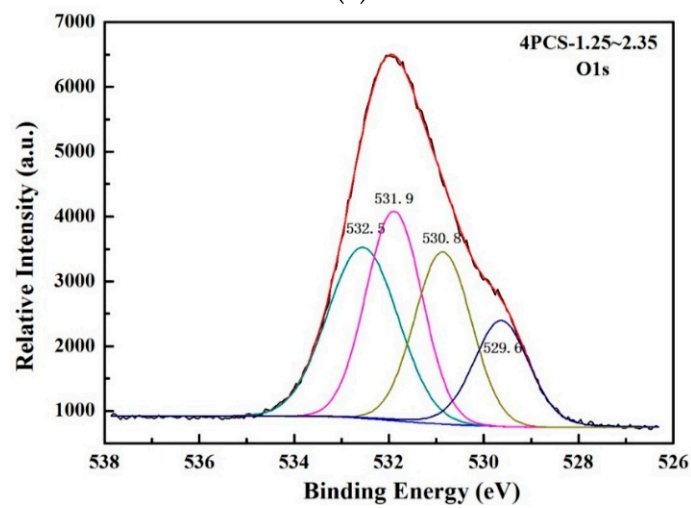

(b)

Figure 6. XPS photographs of PCS (4PCS-1.25 2.35); (a) survey pattern; (b) O1s XPS spectra; XPS: X-ray photoelectron spectroscopy. 


\subsection{Photocatalytic Performance}

The photodecomposition process by PCSs is summarized in Figure 7. Comparing with cementitious materials, the porous structure of PCS could provide more gas diffusion and light transmittance channels which improved the reaction areas and utilization rate of photocatalysts. The photogenerated charges can generate " $\bullet \mathrm{OH}^{\prime}$ radicals and " $\mathrm{O}_{2}{ }^{-"}$ " intermediate species by reacting with absorbed $\mathrm{H}_{2} \mathrm{O}$ and $\mathrm{O}_{2}$ molecules for the photodecomposition of benzene. The mechanism of photocatalytic reaction is shown as follows [4]:

$$
\begin{gathered}
\mathrm{TiO}_{2}+\mathrm{hv} \rightarrow \mathrm{h}_{\mathrm{vb}}^{+}+\mathrm{e}_{\mathrm{cb}}^{-} \\
\mathrm{e}_{\mathrm{cb}}^{-}+\mathrm{O}_{2} \rightarrow \bullet \mathrm{O}_{2}^{-} \\
\mathrm{h}_{\mathrm{vb}}^{+}+\mathrm{H}_{2} \mathrm{O} \rightarrow \bullet \mathrm{OH}+\mathrm{H}^{+} \\
\mathrm{C}_{6} \mathrm{H}_{6}+\bullet \mathrm{O}_{2}^{-}+\bullet \mathrm{OH} \rightarrow \mathrm{CO}_{2}+\mathrm{H}_{2} \mathrm{O}
\end{gathered}
$$

Figure $8 \mathrm{a}$ showed the photocatalytic degradation of benzene on the surface of PCS and control groups. 1PCS-1.25 2.35-UA presented more superior photocatalysis performance (degraded $2 \mu \mathrm{L}$ benzene completely in $350 \mathrm{~min}$ ) compared with other PCSs, proved to be the most efficient one. It was because CS-1.25 2.35 provided more superior pore structure to absorption of gas pollutants, which led to a larger gas-solid contact area between $\mathrm{TiO}_{2}$ and benzene under the same condition. After 1 month of atmospheric environment exposure, 1PCS-1.25 2.35-UA-1 month could still degrade $96 \%$ of $2 \mu \mathrm{L}$ benzene in $400 \mathrm{~min}$. The control group (Surface coating) showed even better photocatalytic activity (degraded $2 \mu \mathrm{L}$ benzene completely in $250 \mathrm{~min}$ ) than 1PCS-1.25 2.35-UA with same amount of photocatalysts because of full exposure of $\mathrm{TiO}_{2}$ particles. However, only after 1 month of atmospheric environment exposure, the photocatalytic activity of "Surface coating" decreased significantly by degrading $67 \%$ of $2 \mu \mathrm{L}$ benzene in $400 \mathrm{~min}$. The reason is that $\mathrm{TiO}_{2}$ is not bound tightly with the surface of cement, which is easily washed off, abraded or enveloped by the cement hydration products. Another control group (Incorporation) showed very little photocatalytic effects because the $\mathrm{TiO}_{2}$ incorporated into cement materials could barely touch the lights. The photocatalytic activity of $\mathrm{TiO}_{2}$ (P25) is also shown in Figure 8a, which is lower than "Surface coating". Despite its higher photocatalytic activity, the agglomeration of $\mathrm{TiO}_{2}$ nanoparticles and the lower adsorption abilities are prevailing in our photocatalytic tests. Besides, the degradation of benzene by 1PCS-1.25 2.35-AC was much slower than 1PCS-1.25 2.35-UA, which indicated more active sites were provided by ultrasonic activation than alkali activation. Thus, ultrasonic activation was selected in subsequent experiments. As indicated in Figure 8 b, the photocatalytic activity of PCS increased gradually when $\mathrm{TiO}_{2}$ concentrations rose from $1 \mathrm{~g} / \mathrm{L}$ to $4 \mathrm{~g} / \mathrm{L}$. However, when $\mathrm{TiO}_{2}$ concentration increased to $5 \mathrm{~g} / \mathrm{L}$, the photocatalytic activity decreased compared with 4PCS-1.25 2.35. Higher concentration of $\mathrm{TiO}_{2}$ solution led to more $\mathrm{TiO}_{2}$ deposition on the surface of $\mathrm{CS}$ and higher photocatalytic activity. Nevertheless, when $\mathrm{TiO}_{2}$ concentration came to $5 \mathrm{~g} / \mathrm{L}$, agglomeration problem of $\mathrm{TiO}_{2}$ was serious, which led to more recombination of electron-hole and difficulties for $\mathrm{TiO}_{2}$ particles to be exposed to the photocatalytic reaction. Hence, 4PCS-1.25 2.35 was chosen as the best material to prepare PCM. 


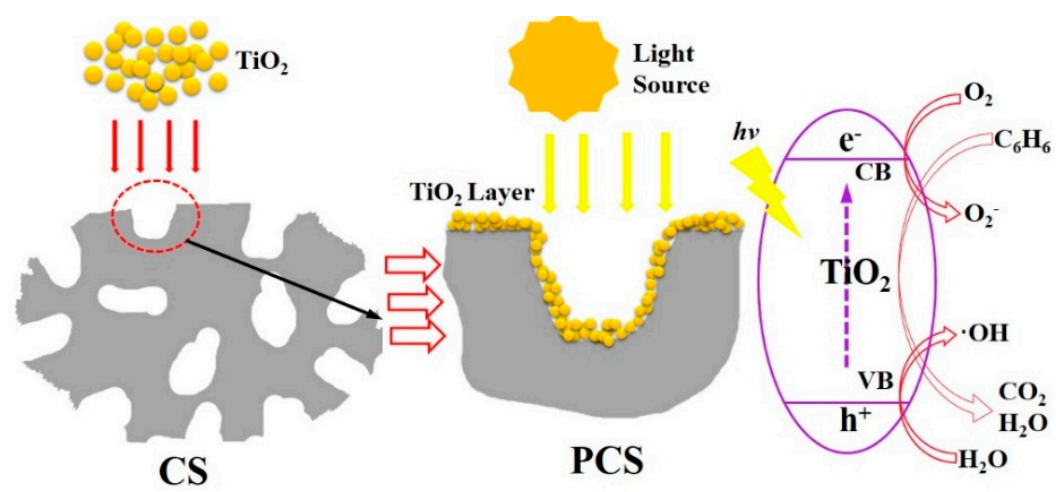

Figure 7. Preparation and catalytic mechanism of PCS.

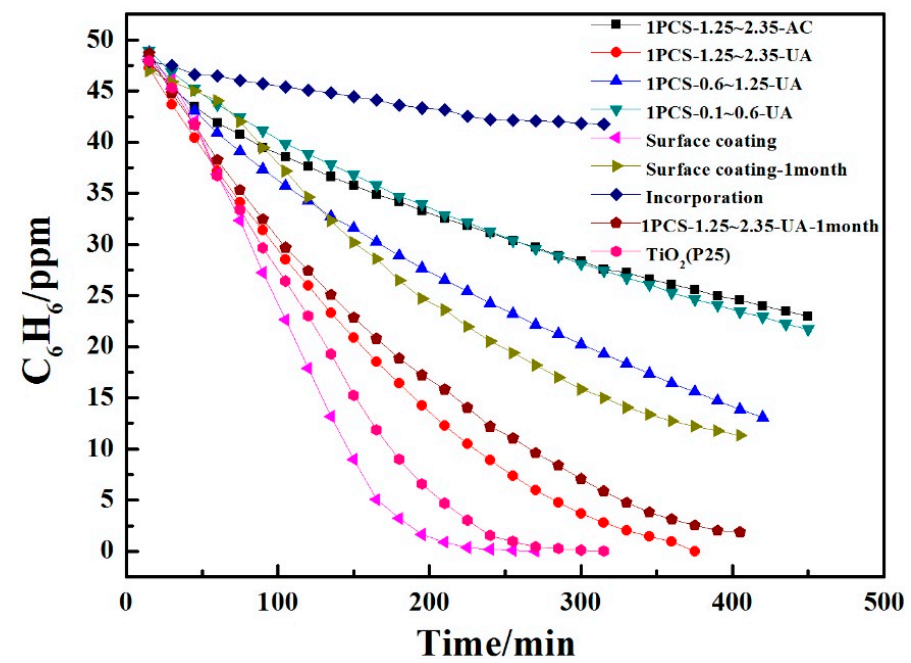

(a)

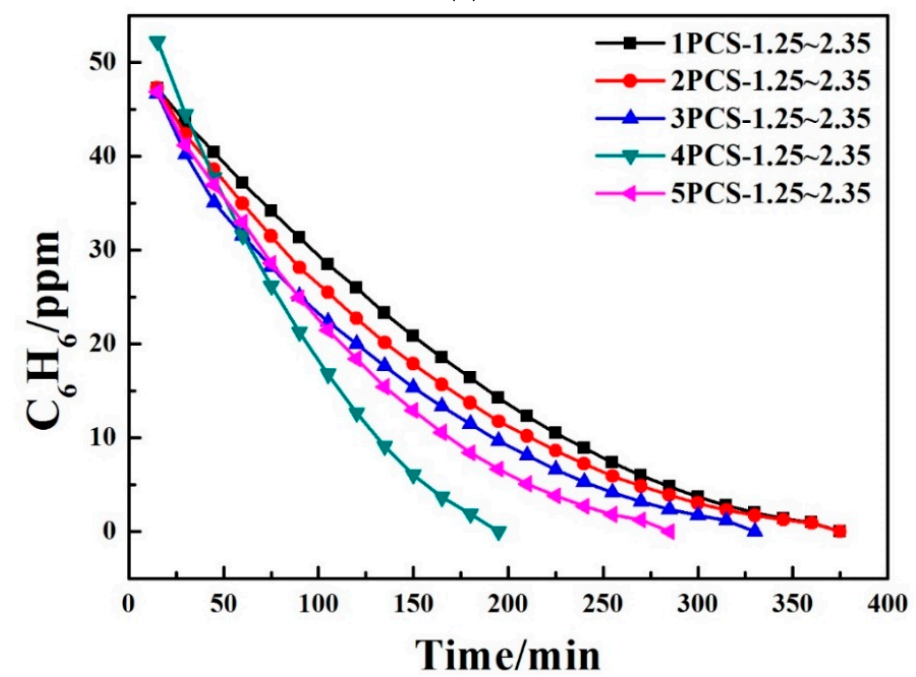

(b)

Figure 8. Photocatalytic activity of PCS to benzene; (a) 1PCS-n-UA (PCS with ultrasonic activation, $\mathrm{n}=0.1 \sim 0.6,0.6 \sim 1.25,1.25 \sim 2.35 \mathrm{~mm}$ ), 1PCS-1.25 2.35-AC (PCS alkali activated), surface coating (the mortars with $\mathrm{TiO}_{2}$ on the surface), surface coating-1month (the mortars with $\mathrm{TiO}_{2}$ on the surface after 1 month of atmospheric environment exposure), Incorporation (the mortars with $\mathrm{TiO}_{2}$ incorporated) and $\mathrm{TiO}_{2}$ (P25); (b) different $\mathrm{TiO}_{2}$ coating concentrations. 
Figure 9 revealed that 4PCS-1.25 2.35 still presented excellent photocatalytic effect after being loaded on the surface of cement materials. As we can see, the adsorption of benzene on surface of mortars without photocatalysts hardly had influence on experiment compared to the photocatalytic effect of samples. It was demonstrated that the surface pores of PCS played an important role in photocatalytic reaction. The presence of PCS increased the reaction area and the loading contents of $\mathrm{TiO}_{2}$ particles, which were beneficial to improve the photocatalytic efficiency. The photocatalytic activity of PCM increased with the increase of PCS on the surface of PCM from $1 \mathrm{~g}$ to $5 \mathrm{~g}$ because the photocatalysts on the surface of PCSs were not covered by cement materials and hydration products and had no agglomeration problem. The PCM still remained high photocatalytic activities after exposure to the natural environment for 6 months (which is marked by PCM-5- 6 months) which is more stable than Surface coating. It is because that the chemical bond ( $\mathrm{Si}-\mathrm{O}-\mathrm{Ti}$ ) between $\mathrm{TiO}_{2}$ and CS could prevent $\mathrm{TiO}_{2}$ particles from peeling from PCS. On the other hand, $\mathrm{TiO}_{2}$ coated on the surface of CS was influenced slightly by the envelope of cement hydration products and the carbonation of cement. However, the prepared PCM was washed and brushed repeatedly for 6 months, and the slight coverage of macro-particles was unavoidable in atmospheric environment exposure, which could slightly decrease the photocatalytic activity of specimen [30].

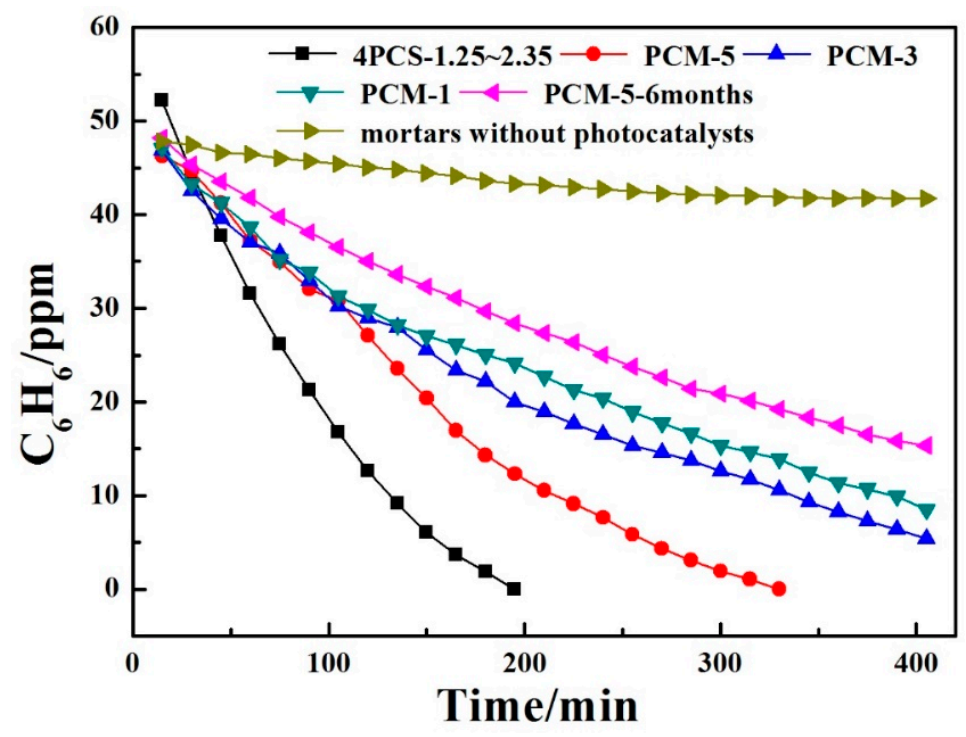

Figure 9. Photocatalytic activity of PCM and mortars without photocatalysts to benzene; PCM-1, 3, 5 (photocatalytic cement materials with 1, 3, $5 \mathrm{~g}$ 4PCS-1.25 2.35).

The resusability performance of catalyst is also an important parameter to evaluate the long-term catalytic performance of photocatalytic material in practical application. Figure 10 showed that time of fully degradation of $2 \mu \mathrm{L}$ benzene by PCS with different $\mathrm{TiO}_{2}$ concentrations and control group. All PCSs still presented excellent photocatalytic activity after being reused for 10 cycles. This might be due to the good stability of substrate and the large bonding force between $\mathrm{TiO}_{2}$ and CS. The control group (Surface coating) showed decreased photocatalytic effects during the cycle experiment. This might be because that high surface energy of $\mathrm{TiO}_{2}$ and low specific surface area of mortar caused the agglomeration of $\mathrm{TiO}_{2}$ particles, which could lead to more recombination of electron-hole and difficulties for $\mathrm{TiO}_{2}$ particles to be exposed to the photocatalytic reaction. Comparing with the previous studies [22,31], our material had an excellent long-term photocatalytic performance with higher retention rate for photocatalytic activity. The reason was that the structures of porous PCS provided higher specific surface area and more gas diffusion channels than cementitious materials and prevented $\mathrm{TiO}_{2}$ particles from being affected seriously by the envelope of cement hydration products 
and the carbonation of cement [32], which improved the reacting areas, utilization rate of catalysts, and enhanced the photocatalytic activity effectively.

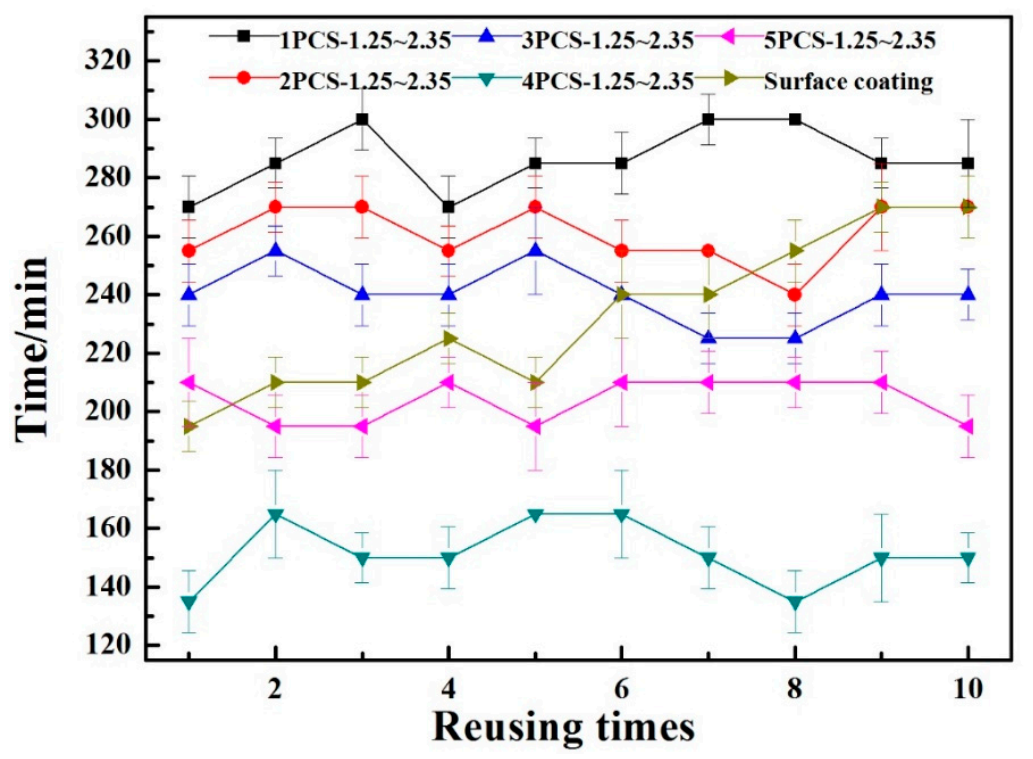

Figure 10. Time of fully degradation of $2 \mu \mathrm{L}$ benzene by mPCS-1.25 2.35 (m = 1 5 g/L) for 10 cycles.

\section{Conclusions}

In this paper, PCS and PCM were prepared successfully. The physicochemical properties, photocatalytic activity and long-term catalytic performance were studied comprehensively. $2 \mu \mathrm{L}$ benzene was degraded completely in $200 \mathrm{~min}$ by $5 \mathrm{~g} 4 \mathrm{PCS}-1.25 \sim 2.35$ and $300 \mathrm{~min}$ by PCM-5, and was still degraded over $80 \%$ in $400 \mathrm{~min}$ by PCM- 5 after exposure to the natural environment for 6 months. The results showed that PCS presented an excellent photocatalytic activity due to abundant pores, stable structure and large reaction area of CS. The detailed results showed that the photocatalytic activity of PCS increased through adjusting CS in appropriate pore structure (more pores in the range of 10 1000 nm, appropriate total porosity and pore volume) and $\mathrm{TiO}_{2}$ in appropriate ratio, which could provide an excessive exposure of $\mathrm{TiO}_{2}$ on the surface and more gas diffusion channels. PCS exhibited an optimal degradation activity to benzene when $\mathrm{TiO}_{2}$ concentration rose to $4 \mathrm{~g} / \mathrm{L}$. However, a fraction of the loaded $\mathrm{TiO}_{2}$ was inaccessible to the reactants or light as the concentration of $\mathrm{TiO}_{2}$ kept increasing (up to $5 \mathrm{~g} / \mathrm{L}$ ). Excessive $\mathrm{TiO}_{2}$ might have serious agglomeration problems, leading to the decreased adsorption rate of air pollutants.

After PCS was loaded on the cement materials, PCM could still present a high catalytic activity. Even after exposure to the natural environment for 6 months, PCM still remained good photocatalytic activity comparing with the cement material with $\mathrm{TiO}_{2}$ on the surface or incorporated. The excellent photocatalytic activity and long-term catalytic performance were attributed to the activation for surface groups and distinctive structure of PCS. The porous structure of PCS increased specific surface areas, gas diffusion and light transmittance channels of PCM, improving the reacting areas and utilization rate of $\mathrm{TiO}_{2}$ effectively. Through this preparation route, more $\mathrm{TiO}_{2}$ particles on $\mathrm{PCS}$ were exposed to environment without being influenced by the envelope of cement hydration products and the carbonation of cement.

Acknowledgments: We gratefully acknowledge the financial support of the National Natural Science Foundation of China (Nos. 51502222 and 51461135005).

Author Contributions: Du Zhao, Peng Liu, Fazhou Wang and Shuguang Hu designed experiments; Du Zhao and Lu Yang carried out experiments; Du Zhao, Peng Liu and Wenqin Zhang analyzed experimental results. Du Zhao wrote the manuscript. 
Conflicts of Interest: The authors declare no conflict of interest.

\section{References}

1. Mendoza, C.; Valle, A.; Castellote, M.; Bahamonde, A.; Faraldos, M. $\mathrm{TiO}_{2}$ and $\mathrm{TiO}_{2}-\mathrm{SiO}_{2}$ coated cement: Comparison of mechanic and photocatalytic properties. Appl. Catal. B 2015, 178, 155-164. [CrossRef]

2. Yang, L.; Wang, F.; Hakki, A.; Macphee, D.E.; Liu, P.; Hu, S. The influence of zeolites fly ash bead $/ \mathrm{TiO}_{2}$ composite material surface morphologies on their adsorption and photocatalytic performance. Appl. Surf. Sci. 2017, 392, 687-696. [CrossRef]

3. Aïssa, A.H.; Puzenat, E.; Plassais, A.; Herrmann, J.-M.; Haehnel, C.; Guillard, C. Characterization and photocatalytic performance in air of cementitious materials containing $\mathrm{TiO}_{2}$. Case study of formaldehyde removal. Appl. Catal. B 2011, 107, 1-8. [CrossRef]

4. Pérez-Nicolás, M.; Balbuena, J.; Cruz-Yusta, M.; Sánchez, L.; Navarro-Blasco, I.; Fernández, J.M.; Alvarez, J.I. Photocatalytic $\mathrm{No}_{x}$ abatement by calcium aluminate cements modified with $\mathrm{TiO}_{2}$ : Improved $\mathrm{No}_{2}$ conversion. Cem. Concr. Res. 2015, 70, 67-76. [CrossRef]

5. Yang, L.; Wang, F.; Shu, C.; Liu, P.; Zhang, W.; Hu, S. An in situ synthesis of Ag/AgCl/ $\mathrm{TiO}_{2} /$ hierarchical porous magnesian material and its photocatalytic performance. Sci. Rep. 2016, 6, 21617. [CrossRef] [PubMed]

6. Boonen, E.; Beeldens, A. Photocatalytic roads: From lab tests to real scale applications. Eur. Transp. Res. Rev. 2012, 5, 79-89. [CrossRef]

7. Folli, A.; Pade, C.; Hansen, T.B.; De Marco, T.; Macphee, D.E. $\mathrm{TiO}_{2}$ photocatalysis in cementitious systems: Insights into self-cleaning and depollution chemistry. Cem. Concr. Res. 2012, 42, 539-548. [CrossRef]

8. Todorova, N.; Giannakopoulou, T.; Karapati, S.; Petridis, D.; Vaimakis, T.; Trapalis, C. Composite $\mathrm{TiO}_{2} / \mathrm{clays}$ materials for photocatalytic nox oxidation. Appl. Surf. Sci. 2014, 319, 113-120. [CrossRef]

9. Folli, A.; Pochard, I.; Nonat, A.; Jakobsen, U.H.; Shepherd, A.M.; Macphee, D.E. Engineering photocatalytic cements: Understanding $\mathrm{TiO}_{2}$ surface chemistry to control and modulate photocatalytic performances. J. Am. Ceram. Soc. 2010, 93, 3360-3369. [CrossRef]

10. Janus, M.; Zatorska, J.; Czyżewski, A.; Bubacz, K.; Kusiak-Nejman, E.; Morawski, A.W. Self-cleaning properties of cement plates loaded with N,C-modified $\mathrm{TiO}_{2}$ photocatalysts. Appl. Surf. Sci. 2015, 330, 200-206. [CrossRef]

11. Rastogi, M.; Vaish, R. Visible light induced water detoxification through portland cement composites reinforced with photocatalytic filler: A leap away from $\mathrm{TiO}_{2}$. Constr. Build. Mater. 2016, 120, 364-372. [CrossRef]

12. Lee, B.Y.; Jayapalan, A.R.; Bergin, M.H.; Kurtis, K.E. Photocatalytic cement exposed to nitrogen oxides: Effect of oxidation and binding. Cem. Concr. Res. 2014, 60, 30-36. [CrossRef]

13. Powers, T.C. Structure and physical properties of hardened portland cement paste. J. Am. Ceram. Soc. 1958, 41, 1-6. [CrossRef]

14. Ramirez, A.M.; Demeestere, K.; De Belie, N.; Mäntylä, T.; Levänen, E. Titanium dioxide coated cementitious materials for air purifying purposes: Preparation, characterization and toluene removal potential. Build. Environ. 2010, 45, 832-838. [CrossRef]

15. Chen, J.; Poon, C.-S. Photocatalytic activity of titanium dioxide modified concrete materials-Influence of utilizing recycled glass cullets as aggregates. J. Environ. Manag. 2009, 90, 3436-3442. [CrossRef] [PubMed]

16. Maury-Ramirez, A.; De Muynck, W.; Stevens, R.; Demeestere, K.; De Belie, N. Titanium dioxide based strategies to prevent algal fouling on cementitious materials. Cem. Concr. Compos. 2013, 36, 93-100. [CrossRef]

17. Wang, F.; Yang, L.; Wang, H.; Yu, H. Facile preparation of photocatalytic exposed aggregate concrete with highly efficient and stable catalytic performance. Chem. Eng. J. 2015, 264, 577-586. [CrossRef]

18. Wang, F.; Yang, L.; Guan, L.; Hu, S. Microstructure and properties of cement foams prepared by magnesium oxychloride cement. J. Wuhan Univ. Technol. Mater. Sci. Ed. 2015, 30, 331-337. [CrossRef]

19. Sugrañez, R.; Álvarez, J.I.; Cruz-Yusta, M.; Mármol, I.; Morales, J.; Vila, J.; Sánchez, L. Enhanced photocatalytic degradation of nox gases by regulating the microstructure of mortar cement modified with titanium dioxide. Build. Environ. 2013, 69, 55-63. [CrossRef]

20. Hu, S.; Yang, T.; Wang, F. Influence of mineralogical composition on the properties of lightweight aggregate. Cem. Concr. Compos. 2010, 32, 15-18. 
21. Olorunsogo, F.T.; Padayachee, N. Performance of recycled aggregate concrete monitored by durability indexes. Cem. Concr. Res. 2002, 32, 179-185. [CrossRef]

22. Yang, L.; Liu, P.; Li, X.; Li, S. The photo-catalytic activities of neodymium and fluorine doped $\mathrm{TiO}_{2}$ nanoparticles. Ceram. Int. 2012, 38, 4791-4796. [CrossRef]

23. Cravanzola, S.; Cesano, F.; Gaziano, F.; Scarano, D. Sulfur-doped $\mathrm{TiO}_{2}$ : Structure and surface properties. Catalysts 2017, 7, 214. [CrossRef]

24. Habibi, M.H.; Mikhak, M. Titania/zinc oxide nanocomposite coatings on glass or quartz substrate for photocatalytic degradation of direct blue 71. Appl. Surf. Sci. 2012, 258, 6745-6752. [CrossRef]

25. Nischk, M.; Mazierski, P.; Gazda, M.; Zaleska, A. Ordered $\mathrm{TiO}_{2}$ nanotubes: The effect of preparation parameters on the photocatalytic activity in air purification process. Appl. Catal. B 2014, 144, 674-685. [CrossRef]

26. Kim, W.B.; Choi, S.H.; Lee, J.S. Quantitative analysis of Ti-O-Si and Ti-O-Ti bonds in Ti-Si binary oxides by the linear combination of xanes. J. Phys. Chem. B 2000, 104, 8670-8678. [CrossRef]

27. Lippmaa, E.; Mägi, M.; Samoson, A.; Engelhardt, G.; Grimmer, A.R. Structural studies of silicates by solid-state high-resolution ${ }^{29}$ Si nmr. J. Am. Chem. Soc. 1980, 102, 4889-4893. [CrossRef]

28. Tokarský, J.; Čapková, P. Structure compatibility of $\mathrm{TiO}_{2}$ and $\mathrm{SiO}_{2}$ surfaces. Appl. Surf. Sci. 2013, 284, 155-164. [CrossRef]

29. Atuchin, V.V.; Kesler, V.G.; Pervukhina, N.V.; Zhang, Z. Ti2p and O1s core levels and chemical bonding in titanium-bearing oxides. J. Electron. Spectrosc. Relat. Phenom. 2006, 152, 18-24. [CrossRef]

30. Maury-Ramirez, A.; Demeestere, K.; De Belie, N. Photocatalytic activity of titanium dioxide nanoparticle coatings applied on autoclaved aerated concrete: Effect of weathering on coating physical characteristics and gaseous toluene removal. J. Hazard. Mater. 2012, 211-212, 218-225. [CrossRef] [PubMed]

31. Yu, C. Deactivation and Regeneration of Environmentally Exposed Titanium Dioxide $\left(\mathrm{TiO}_{2}\right)$ Based Products; Department of Chemistry, Chinese University of Hong Kong: Hong Kong, China, 2003.

32. Wang, F.; Yang, L.; Sun, G.; Guan, L.; Hu, S. The hierarchical porous structure of substrate enhanced photocatalytic activity of $\mathrm{TiO}_{2}$ /cementitious materials. Constr. Build. Mater. 2014, 64, 488-495. [CrossRef]

(C) 2017 by the authors. Licensee MDPI, Basel, Switzerland. This article is an open access article distributed under the terms and conditions of the Creative Commons Attribution (CC BY) license (http:/ / creativecommons.org/licenses/by/4.0/). 